\title{
Radioactivity of Potassium
} Solutions: A Comparison of Calculated Activity to Measured Activity from Gross Beta Counting and Gamma Spectroscopy

Gaylord, R.F.

July 26, 2005 


\section{Disclaimer}

This document was prepared as an account of work sponsored by an agency of the United States Government. Neither the United States Government nor the University of California nor any of their employees, makes any warranty, express or implied, or assumes any legal liability or responsibility for the accuracy, completeness, or usefulness of any information, apparatus, product, or process disclosed, or represents that its use would not infringe privately owned rights. Reference herein to any specific commercial product, process, or service by trade name, trademark, manufacturer, or otherwise, does not necessarily constitute or imply its endorsement, recommendation, or favoring by the United States Government or the University of California. The views and opinions of authors expressed herein do not necessarily state or reflect those of the United States Government or the University of California, and shall not be used for advertising or product endorsement purposes.

This work was performed under the auspices of the U.S. Department of Energy by University of California, Lawrence Livermore National Laboratory under Contract W-7405-Eng-48. 


\title{
Radioactivity of Potassium Solutions: A Comparison of Calculated Activity to Measured Activity from Gross Beta Counting and Gamma Spectroscopy
}

\author{
UCRL-TR-214061
}

\author{
Reginald Gaylord, Chemical Biology and Nuclear Science Division
}

July 2005

\section{INTRODUCTION}

In 1992, the U.S. Department of Energy instituted a Moratorium on the Shipment of Hazardous Wastes from Radiological Areas, generally known as "The Moratorium," which stated that DOE Contractor facilities would not ship waste to any non-DOE-owned off-site facility for treatment or disposal that contained "radioactivity added by DOE activities, within statistical limits. " The condition of "added radioactivity" has generally been defined as a sample showing radioactivity above the sample-specific minimum detectable activity (MDA) for a given type of analysis. In order to meet the requirements of the Moratorium, the Chemistry and Materials Science Environmental Services (CES) laboratories of LLNL use gas proportional counting for gross alpha and beta activity to determine if a given sample contains radioactivity above the detection limit for this method. A major interference with this method is the activity due to Naturally-Occurring Radioactive Material (NORM), such as thorium isotopes in many ceramics, radium in gypsum wallboard, and natural potassium in many samples. NORM may result in a sample having a gross alpha or beta result that is well above detection limit, but not due to "DOE-added radioactivity." Therefore, it is common to use standard inorganic analytical techniques to measure naturally-occurring radioactive elements (potassium in particular) in samples, and determine if the calculated activity from the NORM isotopes can account for the observed activity in the sample.

Potassium is the most common naturally occurring radioactive element on earth, with an average crustal abundance of $2 \%$ by mass ${ }^{2}$. As found in nature, potassium consists of 3 isotopes; K-39 with an isotopic abundance of 0.9326 , K-40, with an isotopic abundance of 0.000117 , and K-41, with an isotopic abundance of 0.0673 . Of these 3 isotopes, K-40 is radioactive with a half-life of $1.277 \mathrm{E}+09$ years. K- 40 decays by $\mathrm{B}-$ emission to $\mathrm{Ca}-40$ in $89.3 \%$ of decays, and by electron capture to $\mathrm{Ar}-40$ in the remaining $10.7 \%$ of decays. In the B- decay, a beta particle with an $\mathrm{E}_{\max }$ of $1.311 \mathrm{MeV}$ is emitted essentially $100 \%$ of the time. The electron capture decay gives rise to the well-known $1460.8 \mathrm{keV}$ gamma ray seen ubiquitously in all background gamma spectra ${ }^{3}$.

One gram of natural potassium contains $1.802 \mathrm{E}+18$ atoms of K-40. This represents 840 picoCi of radioactivity, including 750 picoCi of beta activity. Since the gas proportional method used by CES has a detection limit for beta activity in solids of approximately 3-5 picoCi/g, small amounts of potassium in a sample will obviously produce beta results above background. As another example, seawater, which is typically $390 \mathrm{mg} / \mathrm{L}$ 
potassium, will result in a sample that contains $290 \mathrm{picoCi} / \mathrm{L}$ of beta activity, well above background for gas counting, which is typically $20-50 \mathrm{picoCi} / \mathrm{L}$ for a liquid low in total dissolved solids.

In order to determine if the measured beta activity for a solution containing potassium was exactly as predicted, particularly since the CES gas counter is not calibrated specifically with K-40, an experiment was conducted to compare measured activities from two radioanalytical methods (gamma spectroscopy and gas proportional counting) to calculated activities across a range of potassium concentrations.

\section{MATERIALS AND METHODS}

A NIST-traceable solution of Potassium Chloride $(\mathrm{KCl})$ containing $10000( \pm 30)$ microgram $/ \mathrm{mL} \mathrm{K}$ in $5 \%$ nitric acid was obtained from a commercial vendor (Ultra Scientific, Kingstown, RI). This solution was diluted with 5\% nitric acid using Class A volumetric glassware to produce seven solutions containing concentrations of potassium from $50 \mathrm{mg} / \mathrm{L}$ to $10000 \mathrm{mg} / \mathrm{L}$. Six of the seven solutions were analyzed by inductivelycoupled plasma optical emission spectroscopy (ICP-OES) for confirmation of concentration, with results shown in Table 1.

Table 1. Prepared potassium solutions (theoretical), with ICP-OES confirmation.

\begin{tabular}{|c|c|}
\hline $\begin{array}{c}\text { Known } \\
\text { Concentration } \\
\text { (ppm K) }\end{array}$ & $\begin{array}{c}\text { ICP OES } \\
\text { results } \\
\text { (ppm K) }\end{array}$ \\
\hline 10000 & 9974 \\
\hline 5000 & 5026.8 \\
\hline 2000 & 2065.8 \\
\hline 500 & 493.6 \\
\hline 200 & 189.7 \\
\hline 100 & \\
\hline 50 & 50.6 \\
\hline
\end{tabular}

The four solutions with the highest concentrations, 500- $10000 \mathrm{mg} / \mathrm{L}$, were analyzed by gamma spectroscopy using a High Purity Germanium Photon Detector (HPGE) with $140 \%$ relative efficiency in a low-background counting environment. Spectra were analyzed using GammaVision software (Ametek), using a geometry-specific calibration. Sample volume was $25 \mathrm{~mL}$ and sample count times ranged from 2.8 to 3 days. The spectra were analyzed employing background subtraction from a 5-day background count. For this setup with these count times, the Minimum Detectable Activity (MDA) concentration for $\mathrm{K}-40$ is approximately $700 \mathrm{picoCi} / \mathrm{L}$. 
All seven solutions were then analyzed by gas proportional counting for gross alpha/beta activity. In this analysis, 5 to $25 \mathrm{~mL}$ aliquots of the solutions were evaporated to dryness on stainless steel planchettes to produce uniform, thin deposits. The net weight of each deposit was measured using an analytical balance. These planchettes were then counted on a gas proportional counter (Canberra Eclipse XL/LB, city, state), which was calibrated for alpha efficiency with Am-241, and for beta efficiency with Sr-90/Y-90. Count times were 50 minutes per sample. The results were corrected for alpha and beta efficiency as a function of mass, and alpha-into-beta and beta-into-alpha cross-over as a function of mass, as well as background. The mass curves were prepared using $\mathrm{NaNO}_{3}$ for residual mass. For this counter, mass, geometry, and count time, the Minimum Detectable Activity (MDA) concentration for beta activity was approximately $21 \mathrm{pCi} / \mathrm{L}$, which corresponds to approximately $28 \mathrm{mg} / \mathrm{L}$ of potassium.

\section{RESULTS}

The most concentrated four solutions were analyzed by gamma spectroscopy. The results for the four most concentrated solutions are shown in Table 2 and the attached Figure below. It can be seen that the measured results are in good agreement with the theoretical $\mathrm{K}-40$ activity across the concentration range $500-10000 \mathrm{ppm}$. 
Table 2. Gamma Spectroscopy results for K-40 solution measurements. Results are calculated from the $1460.8 \mathrm{keV}$ photopeak, and are corrected for branching ratio for this gamma ray. The error is the reported measurement error from the gamma ray analysis code, and includes efficiency error, and counting error, including background subtraction.

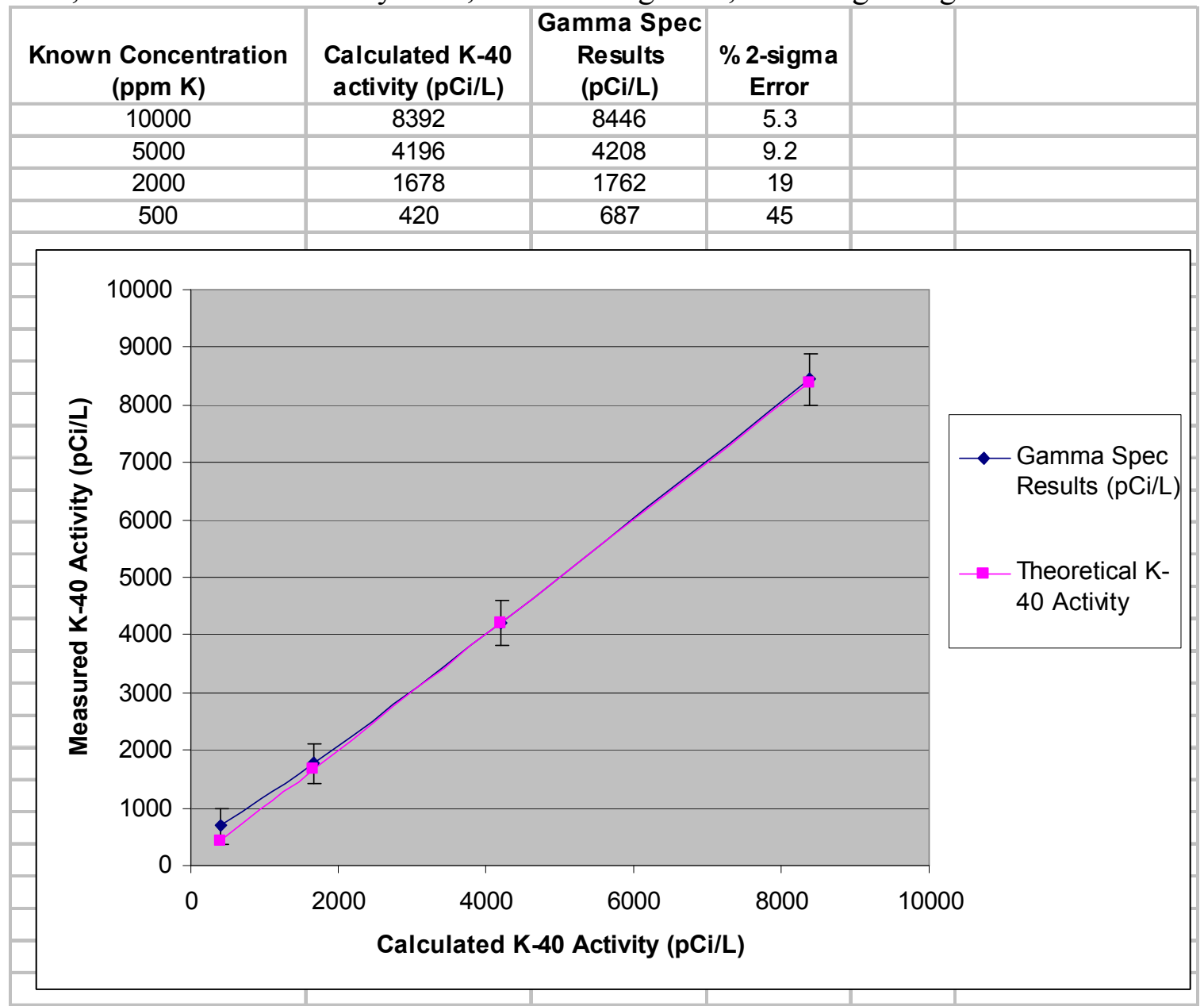

Next, all seven solutions were analyzed by gas proportional counting for gross beta activity, using a count time of 50 minutes. The gross beta results for all solutions are shown in Table 3 and the attached Figure below. It can be seen that there is good agreement between the observed beta activity of the solutions, and the potassium concentration. The reason for the deviation at low $\mathrm{K}$ concentrations is not known, but could be due to the poor statistics for these counts, which were close to detection limit for this method. 
Table 3. Gross Beta activity of Potassium Solutions. The error is measurement error, and includes calibration error and counting error, including background subtraction.

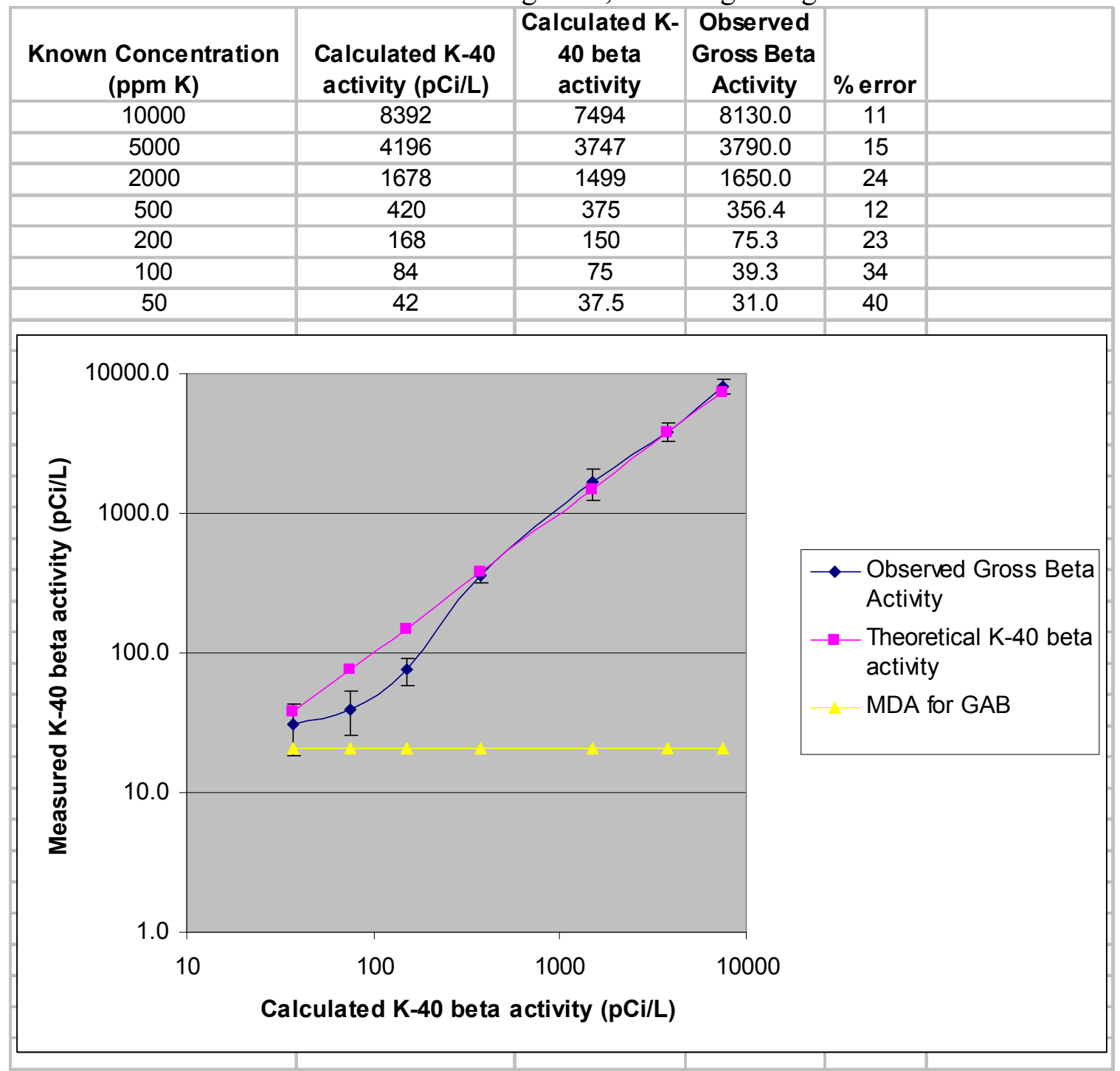

\section{CONCLUSIONS}

Potassium, being ubiquitous and naturally radioactive, is a well-known and common interference in gross beta counting methods. By measuring the observed beta activity due to K-40 in potassium-containing solutions across a wide range of concentrations, it was found that the observed beta activity agrees well with the beta activity calculated from the potassium concentration measured by standard inorganic analytical techniques, such as ICP-OES, and that using the measured potassium concentration to calculate the expected beta activity, and comparing this to the observed beta activity to determine if potassium can account for all the observed activity in a sample, is a valid technique. 
It was also observed that gamma spectroscopy is not an effective means of measuring $\mathrm{K}-40$ activity below approximately $700 \mathrm{pCi} / \mathrm{L}$, which corresponds to a solution with approximately $833 \mathrm{mg} / \mathrm{L}$ total potassium. Gas proportional counting for gross beta activity has a much lower detection limit, typically $20-50 \mathrm{picoCi} / \mathrm{L}$ for a liquid low in total dissolved solids, which corresponds to a potassium concentration of approximately 30-70 ppm K.

\section{REFERENCES}

1. Lytle, J. E., Shipment of Waste Originating in Radiation Control Areas. Memorandum, U.S. Department of Energy, Washington, D.C., May 17, 1991.

2. Lide, D.R., editor, CRC Handbook of Chemistry and Physics, CRC Press, Boca Raton, FL, $75^{\text {th }}$ ed., 1994.

3. Firestone, R.B., editor, Table of Isotopes, Wiley Interscience, New York, NY, $8^{\text {th }}$ ed., 1996. 